\title{
Oleophobic Modification of Hollow Glass Microspheres and Its Effect on the Foaming Capacity and Stability of Foam Extinguishing Agent
}

\author{
Baohua Tang ${ }^{1,2}$ and Zhaoliang $\mathrm{Wu}^{1}$ \\ ${ }^{1}$ School of Chemical Engineering and Technology, Hebei University of Technology, Tianjin 300130, China \\ ${ }^{2}$ Fundamental Department, Chinese People's Armed Police Academy, Langfang, Hebei 065000, China \\ Correspondence should be addressed to Zhaoliang Wu; zhaoliangwu_hebut@163.com
}

Received 9 November 2014; Accepted 19 March 2015

Academic Editor: Guillaume Galliero

Copyright ( $\odot 2015$ B. Tang and Z. Wu. This is an open access article distributed under the Creative Commons Attribution License, which permits unrestricted use, distribution, and reproduction in any medium, provided the original work is properly cited.

We utilized tridecafluorooctyltriethoxysilane (F8261) for the surface modification of hollow glass microspheres (HGM). We then measured the contact angles and the residing time of oil droplets on the HGM surface under different conditions and investigated the effects of the modifier concentration, reaction time and reaction temperature, and other factors on the outcomes of the modification reaction. We also compared the effects of HGM on the expansion ratio and $25 \%$ drainage time of protein foam liquid before and after the modification treatment and investigated the effects of HGM surface oleophobic modification on the foaming capacity and stability of foam extinguishing agent. The results showed that when the F8261 concentration was $1.0 \%$, the temperature was $60^{\circ} \mathrm{C}$, and the ultrasound treatment time was $2.0 \mathrm{~h}$, the contact angle was up to $132.5^{\circ}$, the oleophobic property of HGM could be significantly enhanced, and the foaming capacity and the oil surface stability were significantly improved by the oleophobic modification.

\section{Introduction}

Protein foam extinguishing agent is most commonly used fire extinguishing material when fighting oil fires. It achieves the fire-fighting purpose mainly based on the phenomenon that foam can suppress oil evaporation. It has been found in practice that the thermal stability of regular protein foam is poor. If the supply of foam is of insufficient strength, foam will continue to break down under the effect of flames and heat radiation, and the fire thus can lose control again and is prone to recrudescence $[1,2]$. It has been shown that after adding hollow glass microspheres (HGM) to foam extinguishing agent a stable scaffold of three-phase foam can form inside the foam, so that the thermal stability of foam can been significantly improved [3]. However, since HGM has a strong ability to absorb oil, it was found that the stability of foam added with HGM on oil surface was significantly lower than regular two-phase protein foam, when fighting oil fires [4]. Adding fluorocarbon surfactant to foam extinguishing agent might improve the stability of HGM foam on oil surface. However, it still cannot meet the actual fire-fighting needs [5]. Xiao and Shou found that the modification of ultrafine particle fire extinguishing agent with $1 \%$ fluorocarbon surfactant could increase the oleophobicity of ultrafine particles [6]. This paper used tridecafluorooctyltriethoxysilane (hereinafter referred to as F8261) for the oleophobic treatment of HGM surface. We also investigated the effects of the modifier concentration, reaction time and reaction temperature, and other factors on the modification effect and compared the stability of foam extinguishing agent on oil surface before and after the oleophobic modification.

\section{Experimental Equipment and Materials}

2.1. Experimental Equipment. We used the following equipment: electric stirrer (WH7401290, speed 200 3000 r/min, $30 \mathrm{~cm} \times 35 \mathrm{~cm} \times 76 \mathrm{~cm}$, Tianjin Weihua Experimental Instrument Factory), thermostatic stirrer (Jintan Guosheng Experimental Instrument Factory, Jintan, Jiangsu Province), ultrasonic cleaner (sk3310LHC), sessile drop contact angle 
measuring instrument (JC2000C, Shanghai Powereach Digital Technology Equipment Co.), three-necked flask, $500 \mathrm{~mL}$ beaker, and stopwatch.

2.2. Experimental Materials. The HGM were purchased from the Qinhuangdao Aoge glass beads company. The range of HGM particle size was $10 \sim 100 \mu \mathrm{m}$, the bulk density was $0.18 \sim 0.20 \mathrm{~g} / \mathrm{cm}^{3}$, the floating rate was $\geq 93 \%$, and the crushing strength was 3 5 MPa. Tridecafluorooctyltriethoxysilane (hereinafter referred to as F8261) was from Wuhan De Fu Economic Development Co., Ltd. We used \# 90 kerosene (commercially available), protein foam fire-extinguishing solution (6\% of animal protein liquid with the quality in accordance with the ZBC84007 technology requirement, Fire pharmaceutical factory of the Armed Police Academy), and kerosene (commercially available).

\section{Experimental Methods}

3.1. HGM Surface Oleophobic Treatment. HGM surface oleophobic treatment consisted of the three sequential steps of acid pretreatment, alkaline pretreatment, and surface oleophobic modification.

3.1.1. Acid Pretreatment. An appropriate amount of HGM was added to a mixed solution of concentrated sulfuric acid and $30 \%$ hydrogen peroxide at a ratio of $7: 3(\mathrm{v} / \mathrm{v})$, followed with 20 min of ultrasound treatment. The HGM were then washed, filtered, and dried, in order to remove the impurities adsorbed on the surface of HGM.

3.1.2. Alkaline Pretreatment. An appropriate amount of HGM was added to a mixed solution of $25 \%$ aqueous ammonia, $30 \%$ hydrogen peroxide, and water in a ratio of $1: 1: 5(\mathrm{v}: \mathrm{v}: \mathrm{v})$, followed with $60 \mathrm{~min}$ of ultrasound treatment at $60 \pm 5^{\circ} \mathrm{C}$. The HGM were then filtered and dried.

3.1.3. Oleophobic Surface Modification. Concentrated hydrochloric acid was used to adjust the $\mathrm{pH}$ of the F8261 ethanol solution to about 3.5. An appropriate amount of HGM with surface pretreatment was added, followed with ultrasound stirring for a certain period of time. The HGM were then filtered and dried for use.

3.2. Measurement of the Contact Angle and the Residing Time of Oil Droplets on the HGM Surface. An appropriate amount of HGM was placed on a slide and flattened. A microinjector was use to apply $2.5 \mu \mathrm{L}$ of kerosene in drops onto the powder surface. And the JC2000C sessile drop contact angle measuring device was used to determine the contact angle between the oil droplets and HGM.

An appropriate amount of HGM was placed into a small crucible that was horizontally positioned. A glass slide was used to gently press and flatten the HGM. A syringe was used to apply $0.1 \mathrm{~mL}$ of kerosene in drops onto the powder surface. The morphology of oil droplets in HGM surface was observed and the time that the oil droplets resided on the surface was recorded.

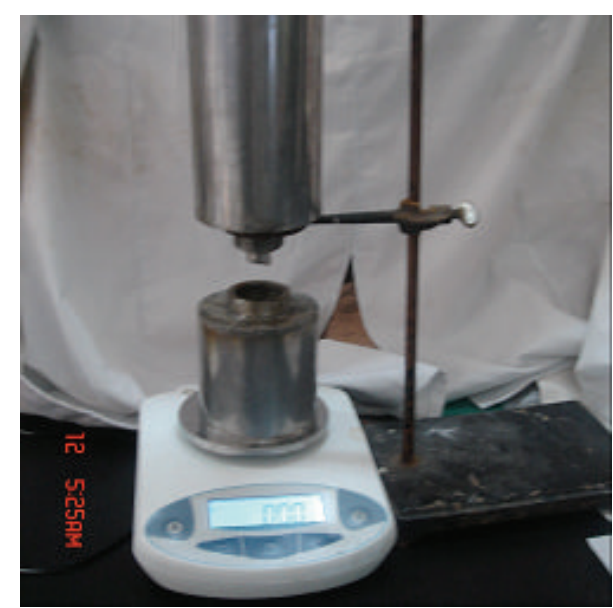

FIGURE 1: Device measuring the foam drainage speed.

3.3. Measurement of the Liquid Drainage Speed. The device measuring the foam drainage speed is shown in Figure 1. The prepared foam was quickly placed in the cylinder on the top of the device, and the drained liquid then flowed into the liquid carrier in the lower part of the device. The readings of the electronic balance were recorded once every $10 \mathrm{~s}$, in order to investigate the foam drainage capacity. The time when $25 \%$ of the liquid is drained is called the $25 \%$ drainage time $\left(t_{25 \%}\right)$.

\subsection{Experiments Measuring the Foaming Capacity of Foam} Fire Extinguishing Agent and the Stability on Oil Surface. The experimental methods for the foaming capacity of foam fire extinguishing agent and the stability on oil surface are as described in the literature $[4,5]$.

\section{Experimental Results and Discussion}

4.1. Effect of F8261 Concentration on the HGM Oleophobic Property. In order to investigate the effect of F8261 concentration on the HGM oleophobic property, $1 \mathrm{~g}$ of HGM with acid and alkaline pretreatments was added into $100 \mathrm{~mL}$ of different concentrations of F8261 ethanol solutions. The ultrasound treatment time and the stirring time were fixed at $2.0 \mathrm{~h}$ and $6 \mathrm{~h}$, respectively. The results of the HGM oleophobic property measurement are shown in Table 1 , where $X$ is the F8261 concentration, $\theta$ is the contact angle, and $t_{s}$ is the residing time of the oil droplets on the HGM surface. Figures 2 and 3 are photos that were taken when HGM modified with different concentrations of F8261 were used for the contact angle measurement.

Table 1 shows that the F8261 concentration can significantly affect the oleophobic property of the HGM surface. When the F8261 concentration was below 1\%, the contact angle and the residing time increased with increasing F8261 concentration. When the concentration exceeded $1 \%$, the F8261 concentration had little effects on the contact angle and the residing time. This is because the modification of HGM by F8261 is a surface chemical reaction. Therefore, when the F8261 concentration is low, the number of fluorocarbon 


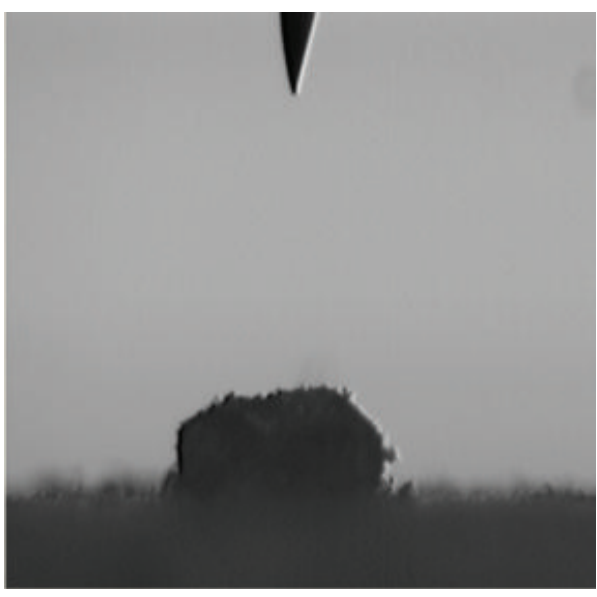

(a)

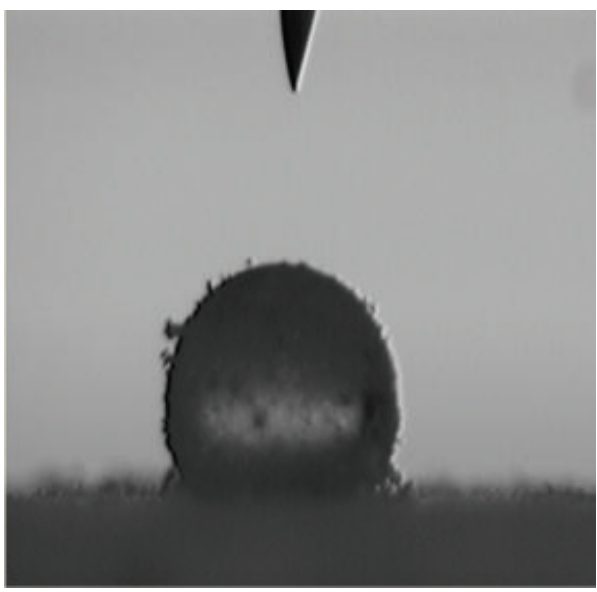

(c)

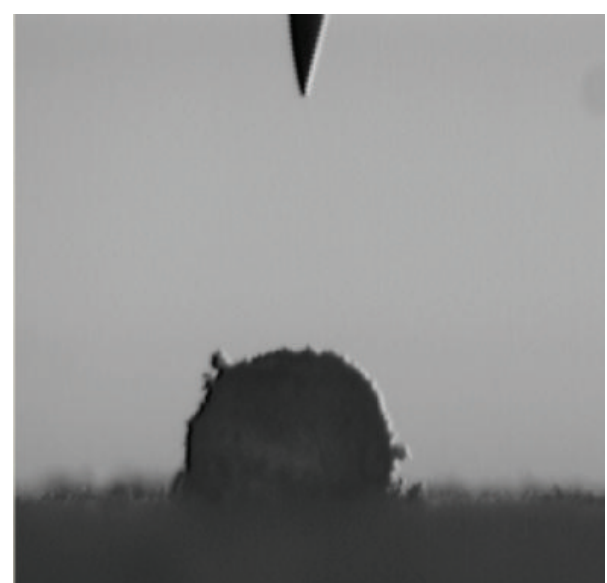

(b)

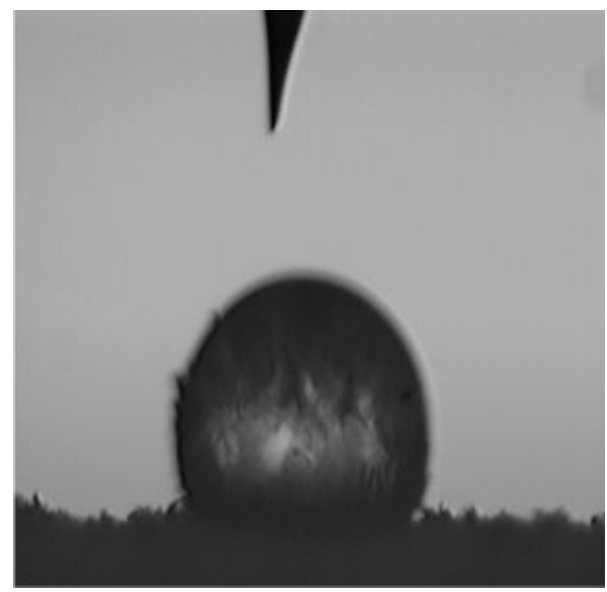

(d)

FIGURE 2: Comparison of the contact angles of HGM modified by different concentrations of F8261 ((a) $0.1 \%$, (b) $0.25 \%$, (c) $0.75 \%$, and (d) $1.0 \%)$.

TABLE 1: Effect of F8261 concentration on the oleophobic property of HGM.

\begin{tabular}{|c|c|c|c|}
\hline$X / \%$ & $\theta /^{\circ}$ & $t_{s} l$ & Morphology of oil droplets on HGM surface \\
\hline 0 & - & - & $\begin{array}{l}\text { Oil droplets immediately penetrate the powder after } \\
\text { contacting with the powder }\end{array}$ \\
\hline 0.1 & 78.5 & $36 s$ & $\begin{array}{l}\text { Oil droplets are fattened-sphere shaped with short residing } \\
\text { time }\end{array}$ \\
\hline 0.25 & 95.5 & $78 \mathrm{~s}$ & $\begin{array}{l}\text { Oil droplets are fattened-sphere shaped with slightly short } \\
\text { residing time }\end{array}$ \\
\hline 0.5 & 118.5 & $386 \mathrm{~s}$ & Oil droplets are hemispherical shaped with long residing time \\
\hline 0.75 & 121.0 & $>72 \mathrm{~h}$ & Oil droplets are roughly spherical shaped \\
\hline 1.0 & 132.5 & $>120 \mathrm{~h}$ & Oil droplets are spherical shaped \\
\hline 2.0 & 133 & $>120 \mathrm{~h}$ & Same as above \\
\hline
\end{tabular}

chains grafted to the HGM surface is low and the HGM oleophobic property is poor (Figures 2(a) and 2(b)). Higher F8261 concentrations lead to higher grafting rates of the reaction and larger contact angles. The oleophobic property of HGM is significantly enhanced and the residing time of the oil droplets on the powder surface is also longer (Figures 2(c) and 2(b)). Once the concentration of F8261 reaches the level that saturates the number of hydroxyl groups on the HGM surface, further increase in the F8261 concentration has little effect on the oleophobic property of the powder.

4.2. Effects of the Reaction Temperature on the HGM Oleophobic Property. In order to investigate the pattern underlying 
TABLE 2: Effect of reaction temperature on the oleophobic property of HGM.

\begin{tabular}{lccl}
\hline$T /{ }^{\circ} \mathrm{C}$ & $\theta /{ }^{\circ}$ & $t$ & Note \\
\hline 36 & 118.5 & $386 \mathrm{~s}$ & $\begin{array}{l}\text { Oil droplets immediately penetrate the powder after contacting } \\
\text { with the powder }\end{array}$ \\
40 & 126.0 & $576 \mathrm{~s}$ & Same as above \\
60 & 128.0 & $>72 \mathrm{~h}$ & Oil droplets are spherical shaped with long residing time \\
80 & 131.5 & $>72 \mathrm{~h}$ & Same as above \\
\hline
\end{tabular}

TABLE 3: Effect of reaction time on the oleophobic property of HGM.

\begin{tabular}{lcc}
\hline$t_{o} / \mathrm{h}$ & $\theta /{ }^{\circ}$ & $t$ \\
\hline 0 & - & - \\
\hline 0.5 & 105.5 & $900 \mathrm{~s}$ \\
1.0 & 112.0 & $\sim 22 \mathrm{~h}$ \\
1.5 & 128.5 & $>43 \mathrm{~h}$ \\
\hline
\end{tabular}

the effects of the reaction temperature on the HGM oleophobic modification, the amount of HGM was fixed at $1 \mathrm{~g}$, the volume of ethanol was $100 \mathrm{~mL}$, the F8261 concentration was $0.5 \%$, the ultrasound treatment time was $2.0 \mathrm{~h}$, and the stirring time was $3.0 \mathrm{~h}$. We compared the oleophobic property of HGM modified under different temperatures and the results are shown in Table 2.

Table 2 shows that the reaction temperature has a great influence on the oleophobic properties of the HGM surface. Under the conditions of same F8261 concentration and reaction time, as the reaction temperature increases, the contact angle between the oil droplets and the powder gradually increases, and the time that the powder remains oleophobic becomes longer. Modification under room temperature did not lead to significant effects on the powder. However, when the reaction temperature exceeded $60^{\circ} \mathrm{C}$, the contact angle of the oil droplet was up to $128.0^{\circ}$, and the time that the powder remained oleophobic was for more than three days.

4.3. Effects of Ultrasound Reaction Time on the Oleophobic Property of the F8261 Modified HGM. When investigating the effects of ultrasound reaction time on the oleophobic property of the HGM surface, the amount of pretreated powder was fixed at $1 \mathrm{~g}$, anhydrous ethanol was fixed at $100 \mathrm{~mL}$, the F8261 concentration was $1.0 \%$, and the reaction temperature was $60^{\circ} \mathrm{C}$. The results are shown in Table 3, and $t_{0}$ in the table is the ultrasound reaction time.

Table 3 shows that ultrasound treatment time has a big impact on the HGM surface oleophobic property. At the same temperature, concentration, stirring, and reaction time, longer ultrasound treatment time leads to better surface modification effect of the powder. This is because the grafting reaction on the HGM surface is slow. The propagation of the ultrasonic wave in the liquid can produce a strong cavitation, which can increase the speed of response. Therefore, longer ultrasonic reaction time leads to a more thorough contact reaction between the HGM and the silane coupling agent, a higher grafting ratio, and stronger oleophobic properties of the HGM.

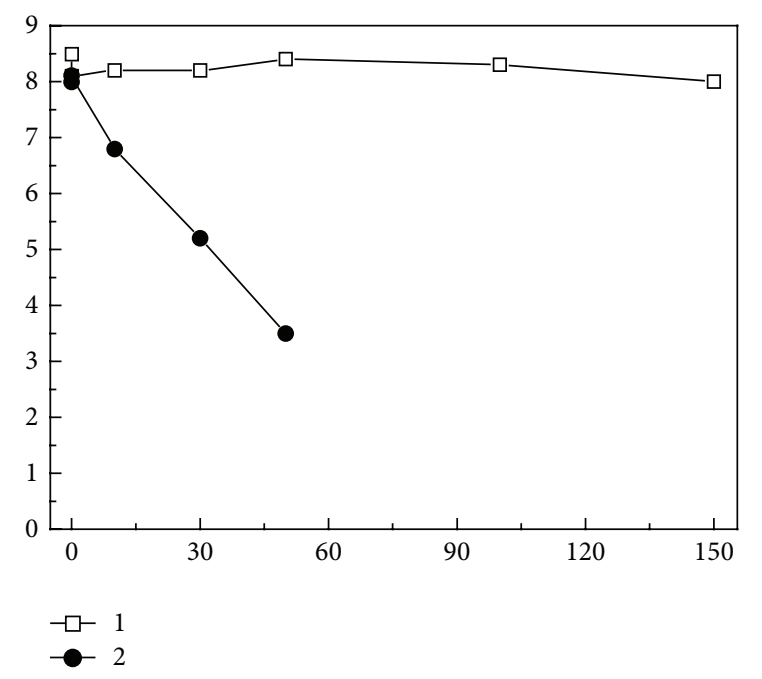

FIGURE 3: Comparison of the expansion ratios of foam after HGM is modified by F8261 (1: modified, 2: unmodified).

4.4. Effect of the Oleophobic Modification of HGM on the Foaming Capacity and Stability of Foam Extinguishing Agent. In order to investigate the effect of the oleophobic modified HGM on the foaming capacity and stability of foam solution, we fixed the concentration of the protein foam extinguishing agent at $10 \%$ and detected the expansion ratios and $t_{25 \%}$ of the protein foam extinguishing agent added with different proportions of HGM before and after oleophobic modification. The results are shown in Figures 3 and 4.

Figures 3 and 4 prove that after the oleophobic modification the foaming capacity and the stability of foam extinguishing agent are significantly improved. Before the modification treatment, the foaming capacity of the foam extinguishing agent was significantly inhibited by the addition of HGM, and the stability was also significantly reduced. The larger the added amount is, the more obvious this effect is. When the proportion of added HGM exceeded $50 \%$, the foam extinguishing agent could not foam effectively and showed poor stability. After the oleophobic modification, the foaming capacity and the stability of foam extinguishing agent are improved significantly. As shown in Figure 4, before the addition of modified HGM, the liquid drainage volume of the ordinary two-phase protein foam increased linearly with time, and $12.97 \%$ of the liquid was drained from the foam within $2 \mathrm{~min}$. In contrast, the liquid drainage speed of the foam added with modified HGM slowed down significantly, and its $t_{25 \%}$ value gradually increased. When the proportion 


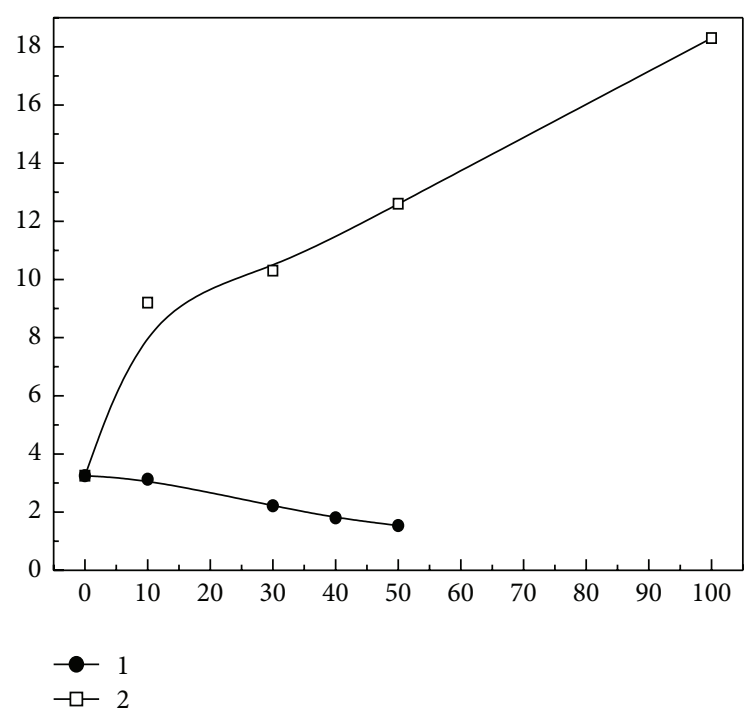

Figure 4: Comparison of $t_{25 \%}$ of foam after HGM is modified by F8261 (1: unmodified, 2: modified).

of modified HGM added was $100 \%, t_{25 \%}$ of the foam was up to $18^{\prime} 15^{\prime \prime}$, around 8.4 times of the ordinary two-phase foam.

This is because the impurities adsorbed on the surface of the unmodified HGM have a certain extent of inhibitory effect on foaming. Larger amounts of unmodified HGM added lead to more significant defoaming effects. After the F8261 oleophobic modification, the HGM surface is coated with fluorine-containing groups, reducing the tension between the beads and the foam interface and significantly reducing the liquid drainage speed of the foam.

4.5. Effect of HGM Oleophobic Modification on the Stability of Foam on Oil Surface. The level of HGM added to the foam system was fixed at $30 \%$, and the concentration of the protein solution was $10 \%$. We compared the trends by which the height of the foam changed over time on oil surface before and after oleophobic modification. And the results are shown in Figure 5.

Figure 5 shows that, compared with the protein foam without the addition of HGM, the presence of HGM led to poor foam stability, and the foam rapidly burst, with the foam height decreased by $83.0 \%$ within $5.0 \mathrm{~min}$. In contrast, for the three-phase foam added with HGM with F8261 oleophobic modification, the height was decreased less than $6 \%$ in $30 \mathrm{~min}$. This indicates that after the oleophobic modification, HGM can significantly enhance the foam stability on oil surface.

This is due to the fact that the unmodified HGM has a strong oil-absorbing ability. Once the foam contacts the oil surface, the HGM keep absorbing oil and thus continuously enter the oil phase. As a result, the foam scaffold is rapidly deconstructed from bottom to top, and the air bubbles inside the foam constantly integrate with each other, leading to increased volume and reduced air pressure inside the bubbles. When exceeding its critical carrying capacity, the upper foam will sink quickly due to gravity, causing the

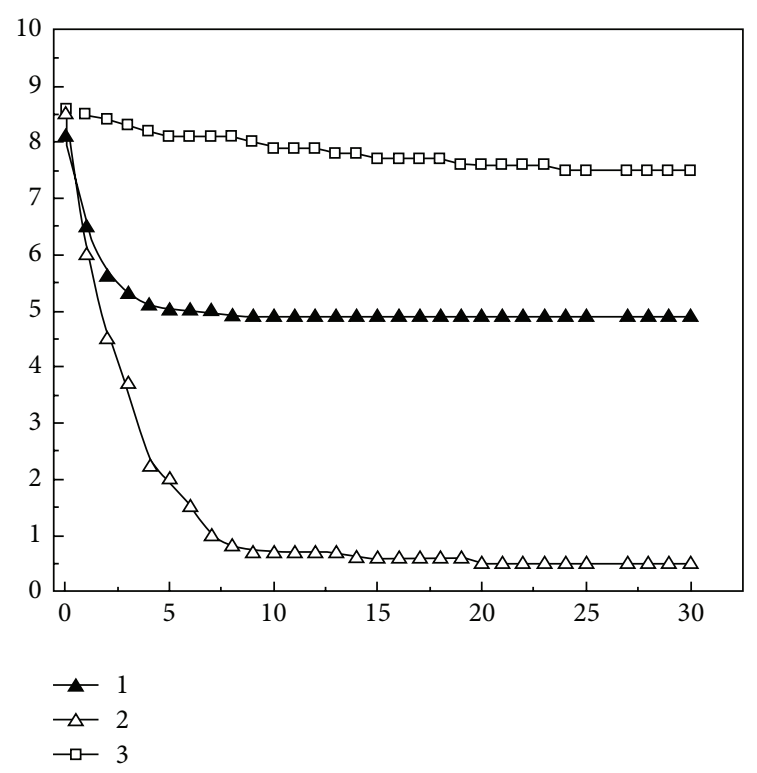

FIGURE 5: Effect of HGM on the stability of foam on oil surface (1: without HGM, 2: unmodified HGM, and 3: modified HGM).

instantaneous reduction of the foam overall height (Figure 6). After being modified by the fluorinated silane coupling agent, the oleophobicity of the HGM is increased. Although the bottom of the foam is still in contact with the oil, the HGM will not enter the oil phase and the phenomenon of bottomup destruction will not occur. Therefore, the foam scaffold is maintained longer, and the foam shows stronger oil surface stability (Figure 6(b)).

\section{Conclusions}

(1) After the treatment of fluorinated silane coupling agent F8261, the HGM oleophobic property can be significantly improved and can be further improved by increasing the F8261 concentration, raising the reaction temperature and increasing the reaction time. Under the conditions of $60^{\circ} \mathrm{C}, 1.0 \% \mathrm{~F} 8261$, and $2.0 \mathrm{~h}$ of ultrasound reaction, the contact angle was up to $132.5^{\circ}$, and the oil droplets could stay on HGM surface over five days.

(2) After the oleophobic modification, the foaming capacity and stability of foam extinguishing agents containing HGM can be significantly improved. After the modification, the amount of added HGM has no significant effect on the foaming capacity of the protein foam liquid. However, the rate by which liquid is drained from the foam slowed down significantly with increasing amounts of HGM, while the 25\% drainage time gradually extended. And larger amount of HGM with oleophobic modification led to greater stability of the foam. When the level of modified HGM reached $100 \%$, the $25 \%$ drainage time of the foam was up to $18^{\prime} 15^{\prime \prime}$ and was about 8.4 times that of the ordinary two-phase foam. 


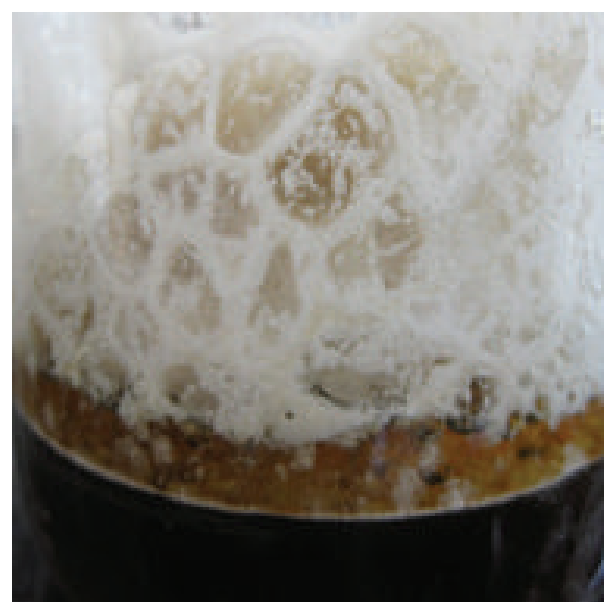

(a)

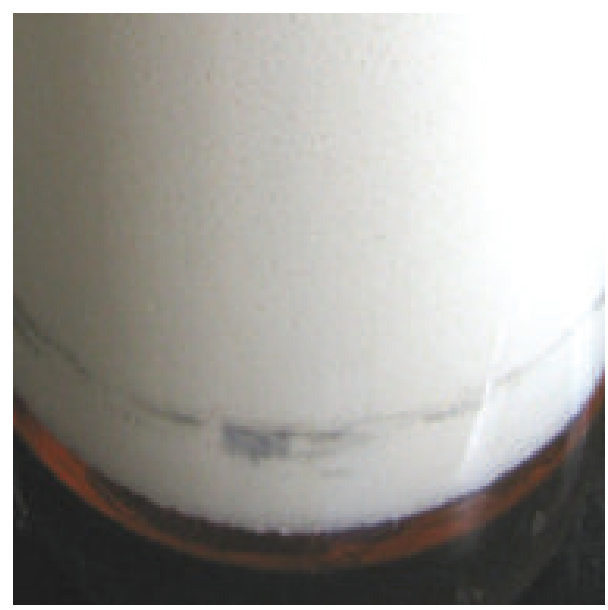

(b)

FIgURE 6: Comparison of the stability of foam after the modification of HGM by F8261 ((a) before modification, (b) after modification).

(3) After the modification of fluorine-containing silane coupling agent, the oleophobic property of the HGM strengthens the skeleton structure inside the foam, and the modified foam can maintain its structure for a long time and demonstrate the superior stability on the oil surface.

\section{Conflict of Interests}

The authors declare that there is no conflict of interests regarding the publication of this paper.

\section{Acknowledgments}

This work was financially supported by the Ministry of Public Security the application of innovation projects (no. 2013YYCXWJXY105), Key Laboratory of the Ministry of Public Security and open project (no. KF201309), and Natural Science Foundations of China (21236001).

\section{References}

[1] B. Y. Lattimer and J. Trelles, "Foam spread over a liquid pool," Fire Safety Journal, vol. 42, no. 4, pp. 249-264, 2007.

[2] C. F. Boyd and M. di Marzo, "The behavior of a fire-protection foam exposed to radiant heating," International Journal of Heat and Mass Transfer, vol. 41, no. 12, pp. 1719-1728, 1998.

[3] C. Weihong, L. Ran, and G. Zidong, "Effects of the hollow glass microsphere on the foaming ability and stability of fire fighting foam," Fire Science, vol. 16, no. 3, pp. 133-136, 2007.

[4] W.-H. Chen, W.-F. Du, and X.-N. Xu, "Experimental study on snti-solubility and snti-burning property of hollow microsphere three-phase foam," Fire Safety Science, vol. 17, no. 1, pp. 15-19, 2008.

[5] W.-H. Chen, W.-F. Du, and W. He, "Effect of fluorocarbon surfactants on anti-solubility and anti-burning property of hollow microsphere three-phase foam," Fire Safety Science, vol. 18, no. 3, pp. 182-186, 2009.

[6] J.-S. Xiao and J. Shou, "Spreading of aqueous mixtures of fluorocarbon hydrocarbon surfactants on oil," Chemical Research and Application, vol. 14, no. 2, pp. 137-140, 2002. 

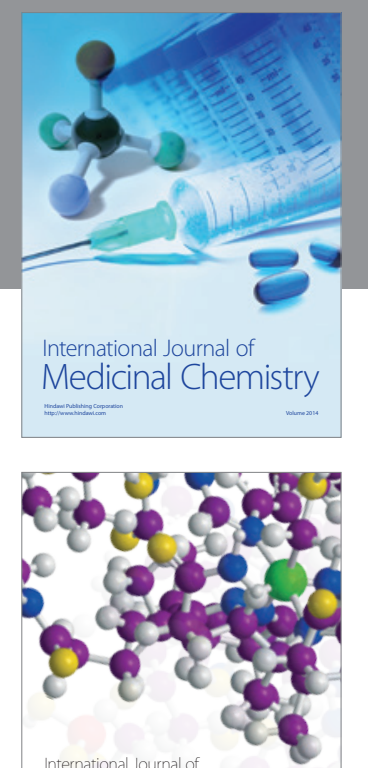

\section{Carbohydrate} Chemistry

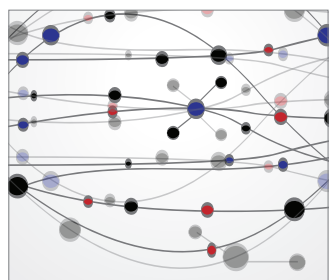

The Scientific World Journal
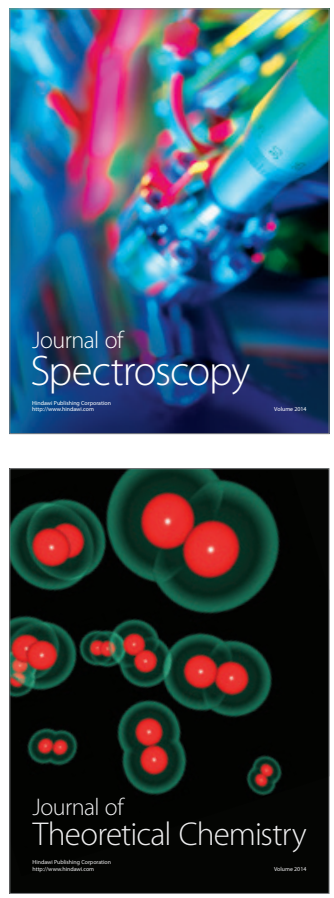
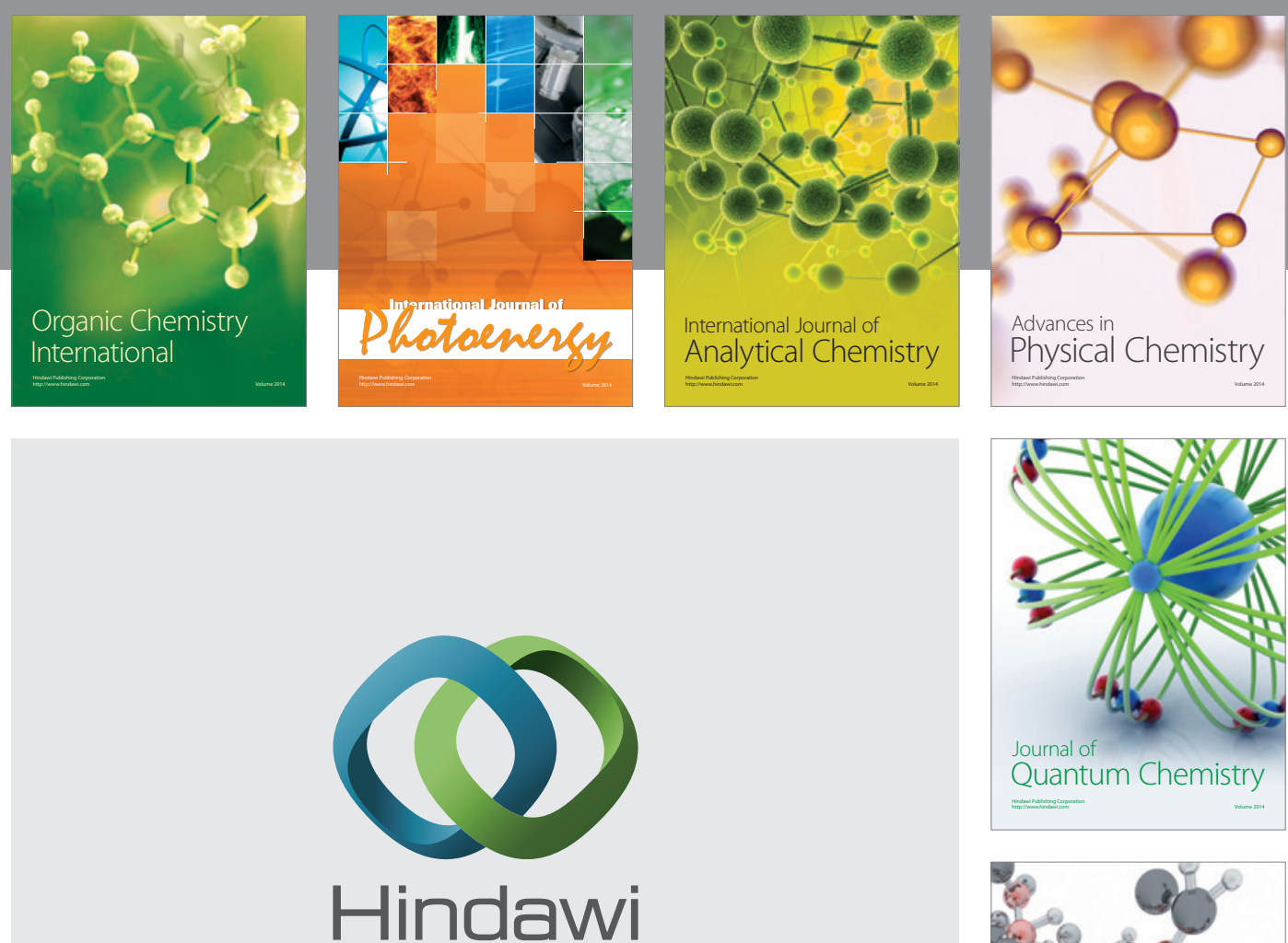

Submit your manuscripts at

http://www.hindawi.com

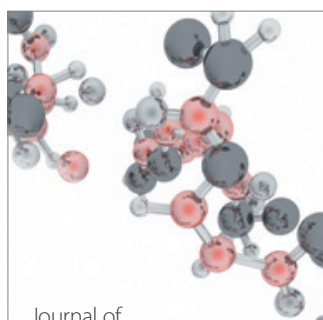

Analytical Methods

in Chemistry

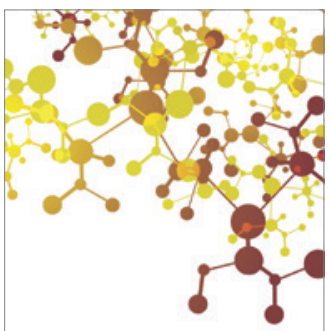

Journal of

Applied Chemistry

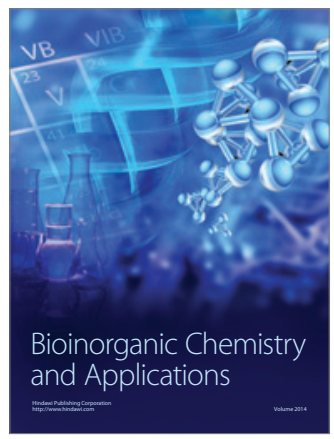

Inorganic Chemistry
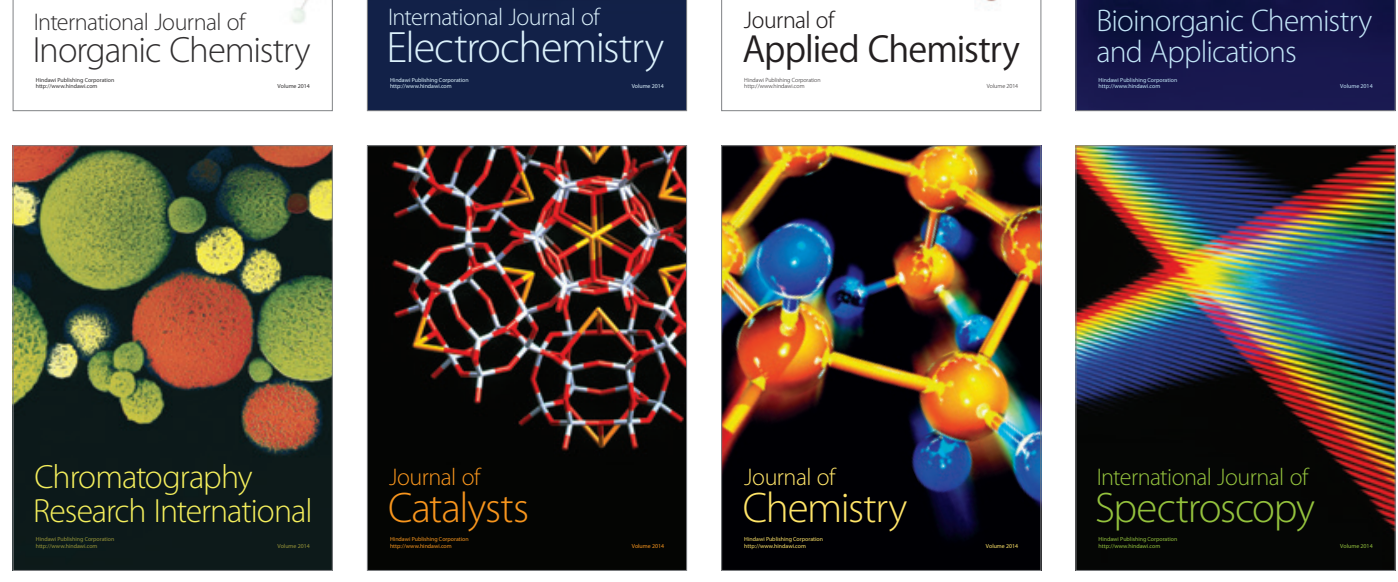